\title{
Adherence to Compulsory Vaccination during Coronavirus Disease-19 Pandemic in Egypt
}

\author{
Nermine N. Mahfouz ${ }^{1}$, Walaa H. Ali ${ }^{1 *}$, Maged A. El Wakeel ${ }^{1}$, Thanaa M. Rabah ${ }^{2}$, Alzahraa A. Elmowafi ${ }^{1}$ Iman H. Kamel ${ }^{1}$ \\ ${ }^{1}$ Department of Child Health, National Research Centre, Dokki, Giza, Egypt; ${ }^{2}$ Department of Community Medicine Research, \\ National Research Centre, Dokki, Giza, Egypt
}

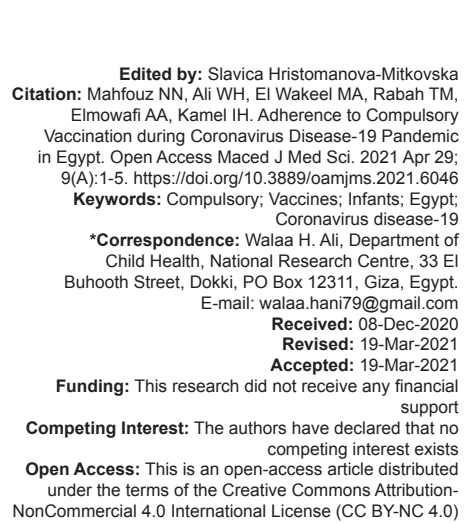

\section{Introduction}

Immunization is the most cost-effective and the highest impact health intervention which reduces hospitalization, treatment costs, and mortality [1]. There are many obstacles against immunization as misinformation about vaccines and disease development after administration of vaccines [2].

Vaccination is proved to be a golden tool for preventing life-threatening infections which is estimated by the WHO to avert between 2 and 5 million deaths annually [3]. Parental attitudes regarding vaccinations are very essential in increasing vaccination rate and compliance to immunization schedule [4].

Parental practice depends on communication between parents and health-care providers as physicians, pharmacists, and nurses [5]. Improving this communication will enrich parents' awareness and knowledge concerning vaccination benefits and hazards [6].

All children should continue to be vaccinated as per their usual schedule with all relevant antigens whenever possible. The decision to maintain or suspend routine immunization services should consider local mandates for physical distancing and health system responses [7].

The pandemic of Coronavirus disease (COVID-19) disease caused by severe acute respiratory syndrome corona virus and the risks it poses to families, communities, and nations have led to massive social and economic consequences, while less likely to cause severe illness in healthy children [8].

Some routine vaccinations for infants and young children were lost due to skipping routine doctor visits and staying home as a result of the corona virus pandemic. The CDC warned that some outbreaks could result from fewer vaccination doses [9].

The maintenance of vaccination services is a vital process for preventing children from communicable diseases and outbreaks during COVID-19 pandemic. However, it is remarkable that obvious declines in pediatric vaccine doses order and administration were observed during lockdown period [9]. Millions of infants and children all over the world have lost and will continue to lose their required obligatory vaccines with a high risk of returning back of some preventable diseases (Vaccine-Preventable Diseases [VPD]) as 
measles and poliomyelitis. The WHO has determined children vaccination as a core health service that must be offered to target children during COVID-19 pandemic [10].

Special attention and extraordinary efforts are demanded to be applied rapidly for vulnerable children with higher risk of morbidity and mortality as refugees and children under custody. On the other hand, mass vaccination campaigns were recommended to be cancelled or postponed to maintain physical distancing and preventing the spread of COVID-19 infection [11].

Our study aimed to assess maternal awareness, commitment and adherence to compulsory immunization schedule during COVID-19 lockdown in Egypt and we hypothesized that some vaccinations were lost due to either lock down or fear from catching infection and that may lead to future outbreaks.

\section{Materials (Subjects) and Methods}

An electronic questionnaire (Google form) was designed to cover a number of aspects starting with an informed consent for participating in the study followed by some non-obligatory personal questions, then two main parts, the first one regarding awareness about COVID-19 and hygienic practices of families, then the second part including questions about vaccination behavior of families since the beginning of the pandemic.

The questionnaire targets parents or caregivers of children in an age group from birth to 2 years old, that is, births from June 2018 to June 2020. It includes multiple choice questions, dropdown and check boxes for an easy smooth accomplishment of the questionnaire in duration between 5 and 7 min before submitting it.

The questionnaire was electronically sent to groups of patients from pediatric and lactation consultants clinics, nurseries and school groups, friends, and families including children with the required age. Collection of data will continue over a period of a month, and then statistically analyzed and correlations of results with other studies done internationally, to come up with important recommendations regarding vaccinations during COVID-19 pandemic.

\section{Statistical analysis}

All test data were collected through online model by Google form. Data were converted and manipulated using SPSS software program version 20.0. Data were analyzed, mean and standard deviation was calculated as regarding quantitative data while qualitative data were presented by number and percent. The quantitative data were compared and $t$ test was applied for normally distributed data or Mann-Whitney for non-parametric data if needed and $P$ value was established to determine the statistically significant difference between groups. While, Chi-square was calculated among groups as regard qualitative data. Odds ratio and 95\% confidence interval were computed accordingly. The difference between the two groups was considered statistically significant when $\mathrm{P}<0.05$, and considered highly statistically significant when $\mathrm{P}<0.01$.

\section{Results}

In our study, age of children ranged between 1 and 24 months, mean was $11.32 \pm 6.8$ months. The study included 805 children, $51.6 \%$ were males. About $76.1 \%$ of our studied group lived in cities. Fathers and mothers' education was university or more in $79.3 \%$ and $73.4 \%$ of participants, respectively (Table 1 ).

Table 1: Socio-demographic characters of studies parents and children

\begin{tabular}{ll}
\hline Variable & Frequency $\mathrm{n}=805$ no. (\%) \\
\hline Child sex & \\
Male & $415(51.6)$ \\
Female & $390(48.4)$ \\
Child age (in months) mean \pm SD & $11.32 \pm 6.8$ \\
$\quad$ Range & $1-24$ \\
Median (IQR) & $10(6-17)$ \\
Residence & \\
City & $613(76.1)$ \\
Village & $192(23.9)$ \\
Father education & \\
Postgraduate & $98(12.2)$ \\
University & $540(67.1)$ \\
Average & $152(18.9)$ \\
Primary or prep & $15(4.3)$ \\
Mother education & \\
Post graduate & $101(12.5)$ \\
University & $490(60.9)$ \\
Average & $198(24.6)$ \\
Primary, preparatory & $16(2.0)$ \\
\hline
\end{tabular}

About $93.7 \%$ of children in the current study received hepatitis $B$ vaccine also; about $96.3 \%$ of them received Bacillus Calmette-Guérin (BCG) vaccine on time. $82.5 \%$ of the children eligible for obligatory vaccines at 2,4 , and 6 months showed adherence to vaccination while, $32.8 \%$ did not receive the obligatory booster dose at 18 months of age. Primary healthcare $(\mathrm{PHC})$ center was the most common place for vaccination (46.2\%). About $51.6 \%$ of children did not receive any addition vaccination. About $70.8 \%$ of children complained of vaccination side effects. About $23 \%$ of who missed vaccinations preferred to post pone until outbreak end while, $27.2 \%$ missed vaccinations due to fear of catching infection. About $84.1 \%$ of parents within the studied group found that it was important to catch up any lost vaccinations (Table 2).

Children over 1 year were noticed to be adherent to vaccinations at $2,4,6$, and 12 compared to those below 1 year $(P=0.001$ and 0.038 , respectively) (Table 3).

No gender differences were found in our studied children regarding adherence to vaccination schedule. 
Table 2: Descriptive data according to vaccination history of studied children

\begin{tabular}{|c|c|}
\hline Variable & Frequency $\mathrm{n}=805$ no. $(\%)$ \\
\hline \multicolumn{2}{|l|}{ The child received $1^{\text {st }}$ dose of hepatitis $B$ vaccine } \\
\hline No, didn't know it was obligatory & $51(6.3)$ \\
\hline Yes & $754(93.7)$ \\
\hline \multicolumn{2}{|l|}{ BCG vaccine on time } \\
\hline No & $30(3.7)$ \\
\hline Yes & $775(96.3)$ \\
\hline \multicolumn{2}{|l|}{ If no, why? (\% out of 30$)$} \\
\hline Child was underweight & $15(50.0)$ \\
\hline Vaccine was unavailable at the primary health-care center & $13(43.3)$ \\
\hline Didn't know it was obligatory & $2(6.7)$ \\
\hline \multicolumn{2}{|c|}{$\begin{array}{l}\text { Did the child receive his obligatory vaccination at } 2,4 \text {, and } 6 \text { months of age (pentavalent } \\
\text { and polio) (\% out of } 771 \text { the children eligible for the vaccine) }\end{array}$} \\
\hline No or Some & $135(17.5)$ \\
\hline Yes & $636(82.5)$ \\
\hline \multicolumn{2}{|c|}{$\begin{array}{l}\text { Did the child receive his obligatory vaccination at } 1 \text { year of age (MMR) (\% out of } 391 \text { the } \\
\text { children eligible for the vaccine) }\end{array}$} \\
\hline No & $72(18.4)$ \\
\hline Yes & $319(81.6)$ \\
\hline \multicolumn{2}{|c|}{$\begin{array}{l}\text { Did the child receive his obligatory booster dose vaccination at } 18 \text { months of } \\
\text { age (trivalent bacterial and trivalent viral and polio) (\% out of } 235 \text { the children eligible for } \\
\text { the vaccine) }\end{array}$} \\
\hline No & $77(32.8)$ \\
\hline Yes & $158(67.2)$ \\
\hline \multicolumn{2}{|l|}{ Place of vaccination } \\
\hline PHC center & $774(96.2)$ \\
\hline Private clinic & $21(2.6)$ \\
\hline VACSERA & $8(1.0)$ \\
\hline Private Hospital & $2(0.2)$ \\
\hline \multicolumn{2}{|l|}{ Did the child receive additional vaccination } \\
\hline Didn't receive any & $415(51.6)$ \\
\hline Chickenpox & $87(10.8)$ \\
\hline Meningococcal & $52(6.5)$ \\
\hline Pneumococcal & $241(30)$ \\
\hline Rota & $314(39)$ \\
\hline \multicolumn{2}{|l|}{ Regularly give the child booster doses for polio and measles } \\
\hline Yes, every time & $384(43.2)$ \\
\hline All polio doses & $57(7.1)$ \\
\hline Some polio doses & $197(24.5)$ \\
\hline Measles & $10(1.2)$ \\
\hline Didn't receive any & $165(20.5)$ \\
\hline \multicolumn{2}{|l|}{ Reason for missing vaccines } \\
\hline Booster dose is not important & $34(4.2)$ \\
\hline Preferred to postpone until outbreak relief & $185(23.0)$ \\
\hline Received all vaccines according to age & $466(57.9)$ \\
\hline Fear of catching infection & $219(27.2)$ \\
\hline $\begin{array}{l}\text { Unavailability of vaccination services because of shutting } \\
\text { down health care centers or private clinics }\end{array}$ & $6(0.7)$ \\
\hline Unavailability of vaccines at $\mathrm{PHC}$ center, & $21(2.6)$ \\
\hline \multicolumn{2}{|l|}{ Vaccination side effects } \\
\hline No & $280(29.2)$ \\
\hline Yes & $525(70.8)$ \\
\hline \multicolumn{2}{|c|}{$\begin{array}{l}\text { After the outbreak is over do you think it is important to catch up your child vaccination } \\
\text { schedule }\end{array}$} \\
\hline Do not know & $113(14.0)$ \\
\hline No & $15(1.9)$ \\
\hline Yes & $677(84.1)$ \\
\hline
\end{tabular}

Residents in cities showed better adherence to vaccination schedule at $2,4,6$, and 12 months compared to residents in villages $(P<0.001)$ (Table 4$)$.

Mothers with high education showed better adherence to vaccination schedule at $2,4,6$, and 12 months of age compared to mothers with average or below average education (Figure 1) while, fathers with high education gave better adherence to vaccination schedule at 2, 4, and 6 months of age than mothers with average or below average education.

Table 3: Comparison between age groups of studied children as regard immunization schedule commitment

\begin{tabular}{|c|c|c|c|c|}
\hline & $\begin{array}{l}\leq 1 \text { year } \\
\text { no. }(\%)\end{array}$ & $\begin{array}{l}>1 \text { year } \\
\text { no. }(\%)\end{array}$ & $p$ value & OR (Cl) \\
\hline \multicolumn{5}{|c|}{$\begin{array}{l}\text { Receive his obligatory } \\
\text { vaccination at } 2,4 \text {, and } 6 \text { months } \\
\text { of age (pentavalent and polio) }\end{array}$} \\
\hline No or some & $120(26.7)$ & $15(4.7)$ & $0.001^{* *}$ & $7.4(4.2-13.0)$ \\
\hline Yes & $330(73.3)$ & $306(95.3)$ & & \\
\hline \multicolumn{5}{|c|}{$\begin{array}{l}\text { Receive his obligatory } \\
\text { vaccination at } 1 \text { year of } \\
\text { age (MMR) }\end{array}$} \\
\hline No & $19(27.1)$ & $53(16.5)$ & $0.038^{*}$ & $1.9(1.0-3.4)$ \\
\hline Yes & 51 (72.9) & $268(83.5)$ & & \\
\hline
\end{tabular}

Table 4: Comparison between studied children according to residence

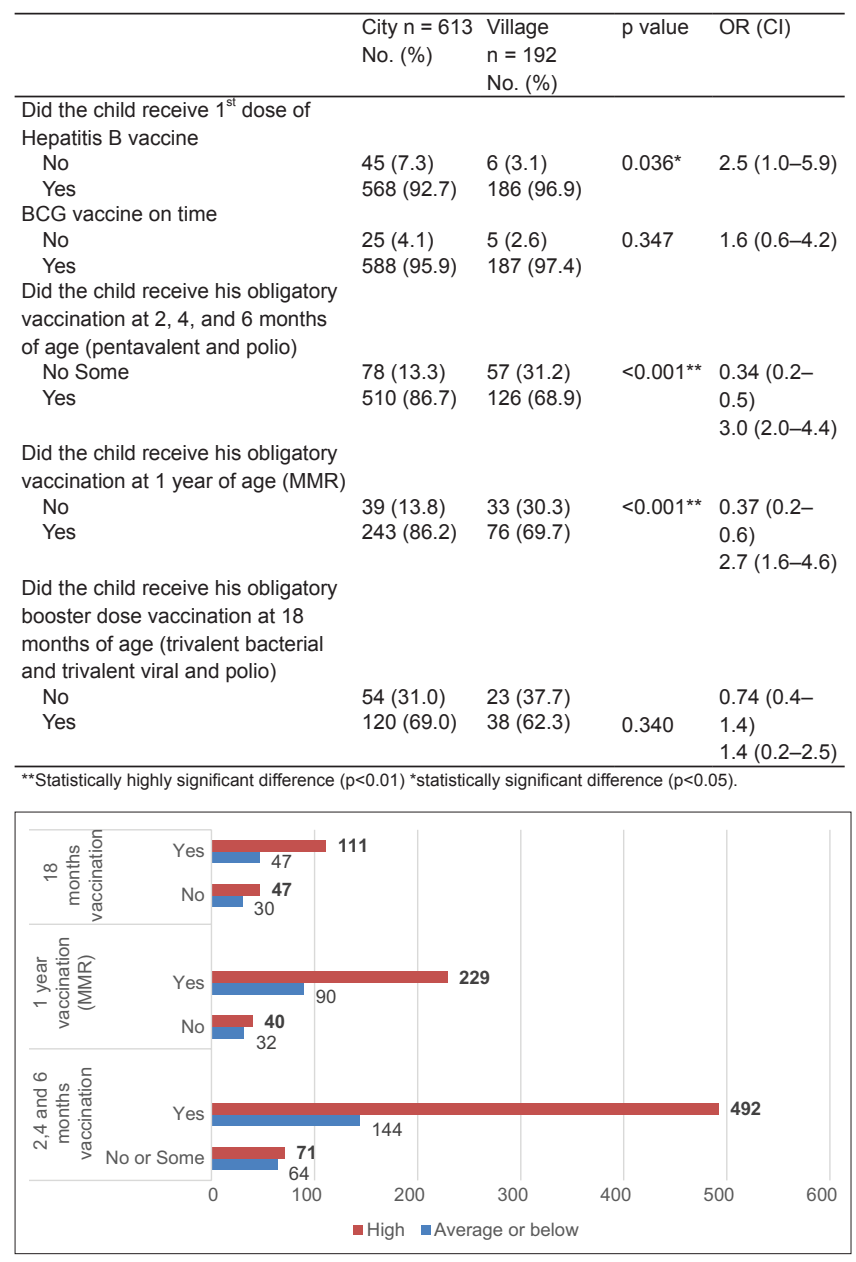

Figure 1: Comparison between studied children according to mother education in obligatory vaccination $(2,4,6,12$, and 18 months) compliance. ${ }^{* *}$ Statistically highly significant difference $(P<0.01)$.

\section{Discussion}

The issue of commitment to routine vaccines has been in focus by the WHO with special emphasis on developing African countries which are at higher vulnerability to VPD [12]. For decades, in Egypt, many studies and national projects have been dedicated to this subject through the National Research Centre to promote health in the community, among which, a large project involving six Egyptian governorates done recently by Salama et al., [13]. Hence, it would be a major fall back, if we prevent a new disease by paving the way back to an old one.

The current cross-sectional retrospective survey in the form of questionnaires explored all the pitfalls and obstacles confronted by caregivers in adhering to the Egyptian immunizations schedule during the COVID19 pandemic. This same topic has been addressed by Abbas et al., [14] who tackled this dilemma of practicing compulsory vaccination during the pandemic. 
The study group involved 805 Egyptian mothers of infants from birth to 24 months (mean age was $11.32 \pm 6.8)$. Gender distribution was almost equal, males were $415(51.6 \%)$ and females were 390 (48.4\%). Both urban and rural areas were presented in a percent of $76.1 \%$ and $23.9 \%$, respectively, with urban predominance.

$\mathrm{PHC}$ center was noted as the most common place for vaccination (96.2\%). This governmental service is free of charge and trusted by parents. About $97.8 \%$ of mothers reported that these centers maintained the same competence during the pandemic as before. However, there were shortening in the resources as $9.7 \%$ of mothers complained of unavailability of vaccines. This crisis was taken into consideration by Nelson who revealed a concern about difficulties in the transferring procedure of vaccines to low- and middleincome countries during the pandemic [15]. While, in a similar study, conducted by Buonsenso et al., [16] in sub-Saharan Africa, the centers were in full capacity and the vaccines were available.

The commitment to vaccination was not influenced by the gender of the infant. On the other hand; it was impacted by the level of parental education and residency. The mothers with higher level of education were found to skip routine vaccines less frequently than those with lower educational level $(P=0.03)$. Furthermore, the number of missed obligatory vaccines was significantly higher in rural compared to urban regions $(P=0.002)$. In accordance, Hussin and Marzo [17] concluded that parental education has great influence on adherence to vaccination schedule. Furthermore, this goes in agreement with Alamri et al., [18] who mentioned the same two main influencers' parental education and residency in their study in Saudi Arabia.

We compared the percent of fulfilled appointments in the immunization schedule for infants. We found that the 2, 4, and 6 months visits were followed by $82.5 \%$, similarly for the $12^{\text {th }}$ month visit was respected by $81.6 \%$ while the adherence to the $18^{\text {th }}$ month booster dose was only $67.2 \%$. Thus, the most frequently skipped vaccine was the obligatory booster dose at 18 months. This was matching with the study done by Buonsenso et al., [16] who found that booster doses were the mostly missed ones. On the other hand, the most frequently administered vaccines were the birth doses of both BCG (96.3\%) and Hepatitis B (93.7\%) as they are given immediately post-delivery; therefore, no extra health-care visit is required. Abbas et al. confirmed the same finding in their large study involving all 54 African countries [14]. The WHO and the UNICEF confirmed that vaccinations should not be skipped meanwhile appropriate precautions should be followed. This will achieve the double gain of averting an outbreak of a VPD and avoiding the exposure to COVID-19 [19].

The COVID-19 pandemic negatively affected the adherence to compulsory vaccines. Among the infants of $>1$ year, $95.3 \%$ received the obligatory vaccination in time at 2,4 , and 6 months of age compared to only $73.3 \%$ of those $\leq 1$ year $(P=0.001)$. This highly significant gap was due to the non-identical timing of these doses in each age group. These visits dated before the pandemic in those $>1$ year while conversely dated during the pandemic for those $\leq 1$ year. The reasons behind skipping vaccines were the preference of $23 \%$ of mothers to postpone vaccination until end of pandemic and $27.2 \%$ of mothers missed vaccination due to fear of catching infection. In accordance, Buonsenso et al., [16] detected a 50-80\% decrement in routine immunization in 2020 in comparison to 2019 $(P<0.005)$. Similarly, in the United States, a drop of $50 \%$ was documented in vaccination with MMR during the COVID-19 pandemic [20].

\section{Conclusion}

COVID-19 pandemic has more threats that cross beyond those of direct viral infection that unfavorably affect children specially those beyond 2 years. Prolonged lockdown and home confinement leads unfortunately to reluctance and lacking in immunization schedule commitment. There are probabilities of increased health risks of avoidable diseases later in life.

\section{Recommendations}

Revising vaccinations and catch up mechanism both are a must. Allowing cooperative network and plan to face quarantine and lockdown impacts as regards children immunizations.

\section{Ethical Considerations}

Parental informed consent was obtained from all study's participants at the beginning of the questionnaire. The ethical committee approved the conduction of this study (Ethical approval number 20093). No names were recorded on the questionnaires and all questionnaires were kept safe.

\section{Acknowledgment}

We are, therefore, grateful to the local researchers and to the collaborators in the society who 
helped in spreading the questionnaires and to parents who have spent some time replying them.

\section{References}

1. Caingles SE, Lobo LE. Survey on the knowledge, attitudes and practices of parents in Barangay $8 a$, district 1 , Davao city regarding their children's immunization. PIDSP J. 2011;12(10):46-53.

2. Alruwaili AA, Abo EL-Fetoh NM, Alruwaili TA, Alanazi WA, Alshammari HA, Alshammari AA. Knowledge, attitude and practice of the parents regarding child vaccinations in Arar, Northern Saudi Arabia. Egypt J Hosp Med. 2018;72(9):5178-82. https://doi.org/10.4103/azmj.azmj_26_17

3. World Health Organization, United Nations International Children's Emergency Fund. Global Immunization Vision and Strategy. Geneva: World Health Organization, United Nations International Children's Emergency Fund; 2015. https://doi. org/10.1007 / 978-1-4020-5614-7_3637

4. Hamid S, Andrabi S, Fazli A, JabeenR. Immunization of children in a rural area of North Kashmir, India: A KAP study. Online J Health Allied Sci. 2012;11(1):10.

5. Al-Lela O. Influence of health providers on pediatrics immunization rate. J Trop Pediatr. 2012;58(6):441-5.

6. Bersen R, Al-Zahmi F, Al-Ali A. Knowledge, attitude and practice towards immunizations among mothers in a traditional city in the United Arab Emirates. J Med Sci. 2011;4(3):114-21. https://doi. org/10.2174 / 1996327001104030114

7. Klein JD, Koletzko B, El-Shabrawi MH, Hadjipanayis A, Thacker N, Bhutta Z. Promoting and supporting children's health and healthcare during COVID-19 - international paediatric association position statement. Arch Dis Child. 2020;105(7):6204. https://doi.org/10.1136/archdischild-2020-319370 PMid:32381517

8. Zhu N, Zhang D, Wang W. A novel coronavirus from patients with pneumonia in China, 2019. N Engl J Med. 2020;382(8):727-33. PMid:31978945

9. Santoli JM, Lindley MC, DeSilva MB, Kharbanda EO, Daley MF, Galloway L. Effects of the COVID-19 pandemic on routine pediatric vaccine ordering and administration - United States, 2020. MMWR Morb Mortal Wkly Rep. 2020;69(19):591-3. https://doi.org/10.15585/mmwr.mm6919e2

\section{PMid:32407298}

10. Hollander JE, Carr BG. Virtually perfect? Telemedicine for COVID-19. N Engl J Med. 2020;382(18):1679-81. https://doi. org/10.1056/nejmp2003539

PMid:32160451

11. El-Shabrawi M, Hassanin F. Infant and child health and healthcare before and after COVID-19 pandemic: Will it be the same ever? Egypt Pediatr Assoc Gaz. 2020;68(1):25. https:// doi.org/10.1186/s43054-020-00039-7

12. World Health Organization. Africa Vaccination Week 2020 Kicks Off as COVID-19 Threatens Immunization Gains. Geneva: World Health Organization; 2020.

13. Salama II, Sami SM, Said ZN, El-Sayed MH, El Etreby LA, Rabah TM. Effectiveness of hepatitis $B$ virus vaccination program in Egypt: Multicenter national project. World J Hepatol. 2015;7(22):2418-26. https://doi.org/10.4254/wjh.v7.i22.2418 PMid:26464758

14. Abbas K, Procter SR, van Zandvoort K, Clark A, Funk S, Mengistu $\mathrm{T}$, et al. Routine childhood immunisation during the COVID-19 pandemic in Africa: A benefit-risk analysis of health benefits versus excess risk of SARS-CoV-2 infection. Lancet Glob Health. 2020;8(10):E1264-72. https://doi. org/10.1101 / 2020.05.19.20106278

15. Nelson R. COVID-19 disrupts vaccine delivery. Lancet Infect Dis. 2020;20(5):546.

PMid:32311326

16. Buonsenso D, Cinicola B, Kallon MN, lodice F. Child healthcare and immunizations in Sub-Saharan Africa during the COVID-19 pandemic. Front Pediatr. 2020;8:517. https://doi.org/10.3389/ fped.2020.00517

PMid:32850565

17. Hussin $\mathrm{H}$, Marzo RR. A literature review of parental barriers to child immunizations. J Crit Rev. 2020;7(3):642-6.

18. ALAmri ES, Horaib YF, Alanaz WR. Knowledge and attitudes of parents on childhood immunization in Riyadh, Saudi Arabia. Egypt J Hosp Med. 2018;70(2):251-6.

19. World Health Organization. WHO and UNICEF Warn of a Decline in Vaccinations during COVID-19. Geneva: World Health Organization; 2020.

20. Carias C, Pawaskar M, Nyaku M, Conway JH, Roberts CS, Finelli L, Chen YT. Potential impact of COVID-19 pandemic on vaccination coverage in children: A case study of measlescontaining vaccine administration in the United States (US). Vaccine. 2021 Feb 22;39(8):1201-04. doi: 10.1016/j. vaccine.2020.11.074. 